\title{
Salve, salve, poesia. Resenha a Bye bye Babel, de Patricia Lavelle
}

Susana Scramim

UFSC / CNPq

Resenha de: LAVELLE, Patrícia. Bye bye Babel. Rio de Janeiro: 7 Letras, 2018.

O livro de poemas Bye bye Babel, de Patrícia Lavelle, já no seu título, traz ao leitor a lembrança de dois filmes emblemáticos tanto para brasileiros

1 Cf. BENJAMIN, Walter. Origem do drama barroco alemão, 1984, p. 189. quanto para franceses, Bye bye Brasil (1979), de Cacá Diegues, e Adieu au langage (2014), de Jean-Luc Godard. Filmes esses que construíram, cada um a seu tempo, imagens da origem, da diversidade e do declínio. O título do livro faz presente em nosso pensamento um tipo de problema criado por falha de comunicação que acarretará uma perda do sentido. As primeiras imagens levam-me à ideia de que a linguagem falhou e falha, porém, ainda, tentará não falhar. Seguindo-se propriamente à leitura dos poemas, organizados em blocos cuja imagem mais forte é a do desaparecimento, outra sensação me invade. Parece que estou diante de poemas cuja temporalidade está marcada por uma metamorfose que, simultaneamente e paradoxalmente, é mitológica e histórica. Penso: o leitor vai precisar lidar com a força dessa aporia, ou seja, tem que lidar com o vir-a-ser e o declinar da linguagem como força que se erige. Refiro-me ao verbo erigir, porque se trata tanto de uma construção da parte do texto que se lê, quanto da leitura que se opera; tanto da construçáo da torre de Babel, quanto da poesia que "vem", a qual se constrói somente quando liberada, após a destruição da torre. A destruição da torre é sintoma de algo que deseja manter uma distância "segura" do "mito", não necessariamente apagá-lo, mas mantê-lo ali para que se aprenda a lidar com sua "presença”. A partir disso, a ideia da destruição da torre, operada no livro Bye bye Babel, funciona muito bem para a liberdade que o poema quer alcançar fora do espaço circular e fechado do mito. Walter Benjamin, em seu estudo sobre o Trauerspiel, ressaltou que a força das lendas heroicas sobre o universo e a divindade foi retomada nos dramas barrocos de modo profano, ou seja, estavam esvaziadas de sua força mitológica e sagrada, no entanto, estavam ali como "forma". A epopeia deixa de ser utilizada como forma de uma história da natureza e passa a ter a função alegórica na obra barroca. Alegoria e epopeia acabam, a partir disso, adquirindo afinidades culturais muito importantes para a arte moderna. ${ }^{1}$ 
2 Cf. NANCY, Jean-Luc. Poème de l'adieu au poème: Bailly. Pođrsie, n. 89, 1999.

3 LAVELLE, Patrícia. Bye bye Babel, 2018, p. 54.

4 Cf. AGAMBEN, Giorgio. $A$ linguagem e a morte: Um seminário sobre o lugar da negatividade, 2006.

5 LAVELLE, Patrícia. Bye bye Babel, 2018, p. 15.

6 Ibidem, p. 16.
A torre que o leitor tem a sua frente no livro de Patrícia Lavelle é a imagem da ruína. Não há ilusão alguma de que o desejo de recuperar a língua pura - o título do último poema, dedicado à Orides, é "Poesia pura" - seja algo passível de ser realizado. Jean-Luc Nancy, em "Poème de l'adieu au poème: Bailly”, ${ }^{2}$ já se referia a um gesto de despedir-se que, simultaneamente, é um adeus e uma saudação; uma saudação a uma nova poesia que se encena no "l'adieu". No livro Bye bye Babel, o que impele a linguagem a seguir em frente é um tipo de hybris do poetar que motiva a tarefa do (im) possível como se fosse uma épica, porém, sabe-se, desde o começo, que esta é e está oca. Instaura-se um tipo de "jogo" de ocupação de lugares entre os tempos mitológico e histórico. Isso fica bastante evidente nos poemas "Kairós", "Cronos", "Ítaca", "Fio da meada" e "Uma lembrança”, como se pode observar nos versos deste último: "Sopro congelado / em bolha de cristal: / era vidro / e não se quebrou / era doce / e não se acabou / era rosa / e nunca murchou" ${ }^{3}$

Antes, já na epígrafe ao livro, reforça-se, com Immanuel Kant, que não há possibilidade plausível de êxito em todas as tentativas da (re)construção da torre. Contudo, a linguagem irá novamente tentar, ela se caracteriza por esse querer-ter-lugar - na compreensão de Giorgio Agamben. ${ }^{4}$ Esse seu querer recobra forças para agir, constatando suas ruínas. Em primeiro lugar, a mais emblemática ruína do mundo histórico torna-se o motivo do primeiro poema do livro de Patrícia Lavelle: a epopeia, pensada a partir do que restou dela, "in nuce". O poema, em seu "quadro" sintético de tensóes, opera mediante a imagem das fantasmagorias das heroínas épicas: Nereidas, Nixes, ou apenas, Sereias e Beatrizes, que se reúnem na figura autoral de Sherazade. Logo em seguida, outra ruína, essa, no entanto, menos problemática em relação à sua discrepância com o mundo histórico, aparecendo, contudo, também sob a forma de fantasmagoria, é o motivo do segundo poema do livro: o "espectro lírico". Novamente sob a forma da alegoria, o poema opera o arranjo de um "quadro" sintético de tensôes: o do náo ter mais lugar - o poema é um soneto - querendo ainda tê-lo, sobrevivendo, retornando, desse modo, como espectro. As imagens de origem e destruição e de destruiçáo como origem vão se multiplicando nos poemas ao modo de imagens dialéticas: o leitor passa pela "arca" - no poema "Arca de Babel" como imagem do barco à deriva e também como origem da deriva: "Nele, as línguas, enroscadas, / pares híbridos e férteis, cresciam e multiplicavam-se" 5 Passa-se também pela imagem do barro - no poema "Utopia de Barro" - como terreno fértil para uma construção efêmera que, entretanto, está permeada pelo movimento rítmico dado pelo encadeamento "quase" popular das redondilhas menores dos versos dessa estrofe que lhe oferecem um "quase" caráter metafísico da verdade: "Era aquilo infância / da razão que aspira: / em suas mãos, argila / em sua voz, Babel”"Em "Arranha-céu", é a 
poesia de Lu Menezes que, com seu céu descascado, denuncia a falácia dessa "bybris" que se alegoriza nos versos de Patrícia Lavelle: "O céu, arranhado, verteu / toda sua transcendência" 7 Trata-se de um diálogo com outra escrita contemporânea - a de Lu Menezes - na qual igualmente se constata o “oco" da epopeia da linguagem em seu desejo de chegar ao céu. Em "Onde o céu descasca", publicado em livro homônimo, Lu Menezes interroga: "No interior / da pizzaria pintada de azul com nuvens / um ponto / onde descola a tinta, onde o céu descasca / denuncia / o sórdido teto anterior /[...]

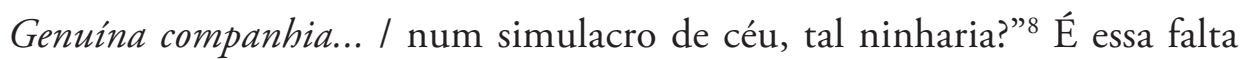
da transcendência que faz com que essa linguagem operada nesses poemas apresente-se com extrema autoironia - “(e nisso essa primeira pessoa / nem é muito singular)" - retomando força justamente quando marcada por um "gosto" todo especial por transformar idealidades em coisas: "Coleciono metáfora antigas / faço mitologias micrológicas, / reciclo toponímias usadas / [...] Assim vou passando de uma coisa-coisa / a outra e outra coisa/"10 Esse "gosto" por materialidades vai construindo um jogo de indeterminação próprio da linguagem figurada sem, no entanto, produzir novos conceitos sobre as coisas com suas figuraçôes, como pude observar nesse poema intitulado "Poética em retalhos", com o qual se encerra a primeira parte do livro: "Ruínas".

O livro Bye bye Babel está divido em cinco partes. Inicia-se com "Ruínas", seguida de "Palavra híbrida", "Eros \& Logos", "Tempos verbais" e "Ecos e vozes". Em todas elas, é possível perceber uma tensão - criada pelo modo de operar a linguagem nos poemas - entre lidar com as abstraçóes da língua e o desejo de fazê-las operar num tempo presente absoluto. Sem a ilusão de alcançar e "resolver" essa dialética, os poemas "apenas" demonstram seu "desejo". Isso fica muito evidente no poema sem título que abre a segunda parte do livro. Ele opera por montagem: junta-se ao verso de Gonçalves Dias, emblemático dessa relação entre um constatar-se "separado" para sempre de sua utópica pátria linguística - "As aves que aqui gorjeiam, / não gorjeiam como lá" - aos seguintes versos: "Heimat é esse lá / exilado / em qualquer / aqui" "11 Além de demonstrar com o segundo bloco de versos o caráter apenas indicativo da linguagem sem qualquer utopia ou ilusão de (re)encontro, o poema opera por montagem; cria, portanto, um "quadro" alegórico em que duas forças opostas entram em luta. O poema encontra sua força, seu conceito e seu destino na tensão entre os contraditórios, operando desse modo como se fosse uma alegoria barroca. Em "Língua materna", diga-se, um dos poemas mais bonitos que li e o mais impressionante do livro como um todo, novamente o leitor tem diante de si esse jogo barroco alegórico. $\mathrm{O}$ poema começa apresentando uma imagem concreta de sua abstraçáo maior: o conceito de história. Jogando com a ambivalência de sentido dada pela pronúncia em português da palavra "ouve" - a qual oscila entre os verbos
7 Ibidem, p. 18.

8 MENEZES, Lu. Onde o céu descasca, 2011, p. 18.

9 LAVELLE, Patrícia. Bye bye Babel, 2018, p. 22.

10 Ibidem, p. 22.

11 Ibidem, p. 25. 
12 Ibidem, p. 26.

13 Ibidem, p. 63.

14 Ibidem, p. 51.

15 GLENADEL, Paula. Rede, 2014. ouvir e haver, respectivamente, na segunda pessoa do singular do modo imperativo do verbo ouvir e a derivaçáo do verbo haver em sua forma impessoal no sentido de existir - o poema cria o seu quadro de tensóes. Trata-se de contrastar dois modos de pensar a história: um com a oralidade, fundada em uma temporalidade da escuta, relativa ao mito, portanto, não discursiva nem científica, e outro a partir dos fundamentos de uma ciência do tempo que se marca pela constatação dos fatos em ordenamento progressivo, ou seja, trata-se de uma temporalidade histórica. De uma ideia de língua como pátria, envolvida na pretensão linguística que ordena a concepção histórica do poema de Gonçalves Dias, passa-se, no "Língua materna", a um confronto entre língua como pátria e língua como mátria, entre uma realidade e uma ilusão. No poema, uma mãe "narra" a seu filho uma história/estória da língua: um tempo de melodias, redondilhas e rimas, tomado como temporalidade da língua pura - musiquinha ruidosa, múltipla e balbuciante - e outro tempo que "já veio entremelado / num outro mais lento, mais longo, sussurrada / monotonia" 12 inserido nessa melodia balbuciante e ingênua. Oferecendo ao conceito de língua esse caráter duplo e, por isso mesmo, doador de multiplicidade.

Bye bye Babel é um livro que produz um movimento incessante do pensamento sobre a linguagem em geral, seus pressupostos e usos. Contudo, o que produz esse pensamento é justamente o uso da linguagem na sua facies mais exuberante e profícua que é a poesia. $\mathrm{O}$ uso que os poemas fazem da linguagem impressiona pela leveza com a qual lidam com os impasses da língua. Investem no confronto sonoro entre palavras, destacando fonemas e seus não-significados e, na contramão destes, destacam os outros "sentidos" produzidos por esses mesmos sons. Em "Ecos", o princípio compositivo do poema demonstra o quanto a potência sonora da língua produz uma sequência infinita e um encadeamento rítmico, tomados ali como produtores da linguagem: "partido de Narciso... "Ciso, siso?" / E nisso ironizo...é, ironizo. / Quem é que sonha em prosa? Eco trova"13

Nos últimos anos, tenho me dedicado à pesquisa com poesia escrita por mulheres. É sempre muito instigante observar o quanto essa escrita coloca constantemente em xeque a relação entre mundo e linguagem, entre arte e realidade. Observo que quase nunca se trata de um trabalho que se "conforma com" o mundo, ao contrário, ele sempre está a tentar se "conformar ao" mundo. É isso que performa o poema de Patrícia Lavelle "Ítaca": "De mão em mão / teci e desteço / o tecido / da nossa trama" ${ }^{14}$ E como o conceito de mundo é amplo e diverso, como escreveu Paula Glenadel na dedicatória ao seu livro Rede (2014), "Ao mundo, seja lá o que isso for, com meus agradecimentos", ${ }^{15}$ essa escrita tem a potência de querer criar novos mundos. A isso - a essa força - denomino feminino. A poesia brasileira contemporânea tem 
sido criada e alimentada por várias autoras com esse tipo de escrita. Trabalho "fino" com a linguagem que medita sobre sua mais potente tarefa: a de nomear o mundo e, portanto, olhar para ele como se fosse a primeira vez e, com isso, (re)criá-lo. Ainda: pensar a língua com essa ambivalente função de reconhecimento e surpresa, estranheza e presença. A poesia de Bye bye Babel não desdenha da exigência maior da poesia contemporânea e, em especial, daquela escrita por mulheres, vale dizer, a de "rendir cuentas"16 de sua consciência de não poder alcançar à totalização do sentido linguístico e tampouco a uma visão geral do mundo e do humano com seus poemas, mas, assim mesmo, investe em tentativas de nomear e (re)criar mundos. A orientação ao precário e a confiança de que nesse lugar o acontecimento da poesia pode advir é uma das singularidades que relacionam a poesia de Patrícia Lavelle ao que venho pensando como "o feminino" e "o contemporâneo". Trata-se de uma busca por outro tipo de relação, entretanto sempre textual, capaz de produzir experiências extratextuais, nas quais estejam presentes a disposição para a interdependência entre biologia e humanismo (zoé y bios) - "Eros \& Logos" é o título da segunda parte de Bye bye Babel -, entre ética e escrita, entre sentido e suspensão da unidade não pensante, entre mimesis e mimetismo, entre fala e discurso.

\section{Referências}

AGAMBEN, Giorgio. A linguagem e a morte: um seminário sobre o lugar da negatividade. Tradução de Henrique Burigo. Belo Horizonte: Ed. UFMG, 2006.

BENJAMIN, Walter. Origem do drama barroco alemão. Tradução de Sérgio Paulo Rouanet. São Paulo: Brasiliense, 1984.

GLENADEL, Paula. Rede. Rio de Janeiro: Confraria do Vento, 2014.

LAVELLE, Patrícia. Bye bye Babel. Rio de Janeiro: 7 Letras, 2018.

MENEZES, Lu. Onde o céu descasca. Rio de janeiro: 7 Letras, 2011.

NANCY, Jean-Luc. Poème de l'adieu au poème: Bailly. Po\&́rsie, n. 89, Paris / Berlin, 1999.
16 "Rendir cuentas": Expressão em espanhol que tem o sentido de produzir um relatório, uma prestação de contas, mas que a utilizo aqui com a ambivalência que o termo "render" oferece às línguas neolatinas, produzindo um encadeamento de sentidos entre "render" pensado também como "relatar", "narrar", como "multiplicar", como tecer entre outros elementos do mesmo processo. 